\title{
ZS Research Square

\section{Comparisons of Clinical Outcomes in Patients Transferred to Combined Therapy with Peritoneal Dialysis and Hemodialysis over those Directly Transferred to Hemodialysis: A Prospective Multicenter Study in Japan}

Yukio Maruyama ( $\square$ maruyama@td5.so-net.ne.jp )

The Jikei University School of Medicine https://orcid.org/0000-0002-5602-8104

Keitaro Yokoyama

The Jikei University School of Medicine

Chieko Higuchi

Tokyo Women's Medical University Medical Center East

\section{Tsutomu Sanaka}

Edogawa Hospital

Yoshihide Tanaka

Toho University School of Medicine

Ken Sakai

Toho University School of Medicine

Yoshihiko Kanno

Tokyo Medical University

Munekazu Ryuzaki

Saiseikai Matsuyama Hospital

Tsutomu Sakurada

St. Marianna University School of Medicine

\section{Tatsuo Hosoya}

The Jikei University School of Medicine

\section{Masaaki Nakayama}

St. Luke's International Hospital

Research article

Keywords: $\beta 2$ microglobulin, combined therapy, dialysate-to-plasma ratio of creatinine (D/P Cr), fluid overload, hemodialysis (HD), inadequate dialysis, peritoneal dialysis (PD), renal replacement therapy (RRT), residual renal function (RRF) 
Posted Date: February 26th, 2021

DOl: https://doi.org/10.21203/rs.3.rs-257954/v1

License: (c) (i) This work is licensed under a Creative Commons Attribution 4.0 International License. Read Full License 


\section{Abstract}

Background. Combined therapy with peritoneal dialysis (PD) and hemodialysis (HD) represents a treatment option for PD patients who cannot maintain adequacy of dialysis. Although several reports have indicated the clinical utility of combined therapy, most such studies have been small-scale, singlecentered, retrospective and before-and-after test investigations lacking a control group.

Methods. We conducted a prospective, multicenter, observational cohort study of 176 incident PD patients and compared patient survival and time-course changes in clinical parameters between patients switched from PD alone to combined therapy and patients switched directly to HD.

Results. During a median follow-up of 41 months, 47 patients transferred to combined therapy and 35 patients transferred directly to HD. Among patients transferred to combined therapy, $66 \%$ transferred because of inadequate dialysis, and/or fluid overload, compared to only $29 \%$ among patients directly transferred to HD. Five patients died after transfer to HD alone, whereas 1 patient died after transfer to combined therapy. Although mortality was greater among patients transferred to HD directly than among patients transferred to combined therapy, this difference disappeared after matching for fluid overload and/or inadequate dialysis.

Conclusion. This is the first report comparing clinical outcomes for patients on PD alone transferred to combined therapy with those for patients directly transferred to HD. Although comparison of patient survival was difficult because of the small number of deaths, PD patients suffering from inadequate dialysis and/or volume overload could clearly continue PD therapy safely by switching to combined therapy. Further study with a larger number of outcomes is needed.

\section{Background}

Peritoneal dialysis (PD) is valuable for patients who have newly developed a need for renal replacement therapy (RRT) to preserve residual renal function (RRF), quality of life (QOL), and hemodynamic stability as compared to hemodialysis (HD) (1). However, the management of PD becomes more difficult as RRF declines and peritoneal function deteriorates, and inadequate dialysis and/or fluid overload become clinically evident. Several guidelines recommend that optimal small-solute clearance, indicated as Kt/V $\geq$ 1.7 , and euvolemia should be maintained by monitoring both urine volume and amount of ultrafiltration achieved (2-5).

Patients who become unmanageable by PD alone need to change the modality of RRT. Although such patients are often transferred directly to HD, transfer to combined therapy with PD and HD (generally consisting of 5- 6 days of PD and one HD session per week) is another option. Combined therapy was introduced in the 1990s and has been rapidly spreading in Japan, and an estimated 1,800 patients (20\% of all PD patients) have been on this therapy in 2017 (6). Combined therapy has been covered by the National Health Care Insurance System in Japan since April 2010. Several reports have demonstrated the clinical utility of combined therapy for correction of inadequate dialysis and/or fluid overload (7-11). We 
established the Evaluation of the Adequacy of Renal replacement Therapy (EARTH) study group to clarify the clinical utility of combined therapy in 2008 and published a retrospective multicenter study of 104 patients switched from PD alone to combined therapy with PD and HD (7). However, previous studies, including that previous investigation, have targeted only patients starting combined therapy with PD and $\mathrm{HD}$ and have compared several clinical parameters between before and after switching to combined therapy.

The chief aim of this prospective, multicenter, observational cohort study including incident PD patients was to compare patient survival and several clinical parameters between patients switched from PD alone to combined therapy and those directly switched to HD.

\section{Methods}

We conducted a prospective, multicenter, observational cohort study that included 176 patients who started PD as first RRT between January 2011 and December 2016 at Jikei University Hospital and three branch hospitals, Tokyo Medical University Hospital, Tokyo Women's Medical University Medical Center East, Tokyo Saiseikai Central Hospital, Toho University Omori Medical Center and St. Marianna University Hospital. The ethics committee at Jikei University Hospital and each participating hospital approved this study protocol, and all patients provided written informed consent to participate.

Patient data, including age, sex, cause of end-stage renal disease (ESRD), comorbidities, physical examination, details of dialysis prescription and laboratory findings at the start of PD and every year were registered using an anonymized case report form. The outcomes of interest were patient survival and changes in several physical and laboratory parameters. Regarding comorbidities, cardiovascular disease was defined as heart failure, acute myocardial infarction, arrhythmia or conductive disturbance, valvular disease and other heart disease, whereas cerebrovascular disease was defined as subarachnoid hemorrhage, cerebral hemorrhage, cerebral infarction and other cerebrovascular disease. Blood tests for hemoglobin, total protein, serum albumin, urea nitrogen, creatinine and $\beta 2$ microglobulin were performed using standard laboratory techniques at each center. Since no definite criteria for changing dialysis modality were applied, the timing of changing modality and selection of the type of the new modality, particularly combined therapy or HD alone, were left to the discretion of the treating physicians. If a patient changed dialysis modality, the date of transfer and reasons for changes (including inadequate dialysis, fluid overload, both or other reasons) was required. Inadequate dialysis was defined as laboratory test abnormalities including total $\mathrm{Kt} / \mathrm{V}<1.7$, higher $\beta 2$ microglobulin levels and appearance of uremic symptoms (including deterioration of nutritional status, decreased subjective global assessment (SGA) score, persistent anorexia, erythropoietin-stimulating agent (ESA)-hyporesponsive anemia and restless leg syndrome). Fluid overload was defined as higher blood pressure (BP) or drug-resistant hypertension, heart enlargement or pleural effusion on chest $\mathrm{X}$-rays and persistent peripheral edema or anasarca. The dialysate-to-plasma creatinine ratio (D/P Cr) was obtained from a peritoneal equilibration test (PET). In the PET as originally described, ultrafiltration capacity is the net volume of ultrafiltration 
achieved at $4 \mathrm{~h}$ using a $2.27 \%$ glucose exchange $(3,5)$. Kt/ $\mathrm{V}$ was calculated using guidelines from the Japanese Society for Dialysis Therapy (JSDT) (5).

\section{Statistical analysis}

Data are presented as mean \pm standard deviation (SD) or median and interquartile range (IQR), as appropriate. Values of $p<0.05$ were considered statistically significant. Differences among the three groups, including patients who continued PD, those who transferred to combined therapy with PD and HD and those who directly transferred to HD, were evaluated using one-way analysis of variance (ANOVA) or the non-parametric Kruskal-Wallis test, as appropriate. Chi-squared tests were used for the comparisons of nominal variables. Paired data were analyzed using the paired t-test or Wilcoxon signed-rank test, as appropriate. Comparisons of temporal changes in clinical parameters between patients transferred to combined therapy and those directly transferred to HD were assessed using repeated-measures two-way ANOVA. Kaplan-Meier survival analysis was used to compare patient survival between three groups. All statistical analyses were performed using JMP for Windows version 13.2.1 software (SAS Institute Inc., Cary, NC, USA).

\section{Results}

Table 1 lists baseline characteristics of 176 patients with incident PD (mean age, $60 \pm 15$ years; male, 71\%). Causes of ESRD comprised chronic glomerulonephritis (CGN) in 56 patients (32\%), diabetes in 66 (38\%), hypertension in 27 (15\%), polycystic kidney disease (PKD) in $5(3 \%)$ and other or unknown in 22 (13\%). Prevalences of cardiovascular disease, cerebrovascular disease and malignant disease were $12 \%$, $9 \%$ and $6 \%$, respectively. At the start of PD, urine volume, urea nitrogen and serum creatinine were $1230 \mathrm{~mL} /$ day (IQR $980-1800$ ), $79.7 \pm 28.6 \mathrm{mg} / \mathrm{dL}$ and $8.9 \pm 2.4 \mathrm{mg} / \mathrm{dL}$, respectively. Regarding PD-related tests, total, renal and PD Kt/V were $1.67 \pm 0.49,0.82 \pm 0.41$ and $0.84 \pm 0.34$, respectively. Baseline D/P Cr obtained from the PET was $0.60 \pm 0.12$.

Median follow-up was 41 months (IQR, 25-67 months). Among the 176 enrolled patients, 82 patients were transferred from PD alone to other modalities, comprising 47 patients transferred to combined therapy with PD and HD and 35 patients directly transferred to HD, with times to transfer of 28 months (17-44 months) and 33 months (16-45 months), respectively. Among the 47 patients who transferred to combined therapy, 22 patients subsequently transferred to HD alone. Patients transferred to combined therapy were younger and had a higher body mass index (BMI) than those directly transferred to HD or those who continued PD alone, whereas no significant differences in other clinical parameters at the start of PD were seen between the three groups (Table 1). Reasons for changes in dialysis modalities are shown in Fig. 1. Among the patients transferred to combined therapy, $66 \%$ transferred because of inadequate dialysis, fluid overload or both, whereas only $29 \%$ transferred because of these reasons among the patients directly transferred to $\mathrm{HD}(\mathrm{P}<0.01$, Chi-squared test). Other reasons included inguinal hernia operation $(n=1)$, exit-site infection $(n=1)$, preparation for renal transplantation $(n=1)$, initiating dialysis with combined therapy $(n=1)$ and unknown reason $(n=12)$ among patients transferred to 
combined therapy, and difficulty performing PD $(n=7)$, pleuroperitoneal communication $(n=4)$, peritonitis $(n=4)$, exit-site infection $(n=3)$, abdominal disorder or surgery $(n=3)$ and unknown reason $(n=4)$ among those directly transferred to HD. Regarding dialysis prescription, $93 \%$ of patients on combined therapy received 4-h HD using high-flux dialyzers once weekly, whereas the remaining 7\% received 4-h online hemodiafiltration once weekly. In general, PD was not carried out on the day of the HD session, and 35\% of patients also did not perform PD on some other day each week, defined as a 'PD holiday'.

Table 2 shows comparisons of changes in clinical and biochemical parameters between patients transferred to combined therapy and those directly transferred to HD. BMI and urinary volume decreased after changing dialysis modalities in both groups. Urea nitrogen and serum creatinine decreased among patients directly transferred to HD, whereas no significant change was apparent among those transferred to combined therapy. BP decreased among patients transferred to combined therapy, but did not change significantly among those directly transferred to HD. Hemoglobin levels increased among patients transferred to combined therapy, whereas they no significant change was seen among those directly transferred to HD. Serum albumin and $\beta 2$ microglobulin did not change significantly in either group. Overall, degrees of change in diastolic BP, urea nitrogen and serum creatinine were significantly different between groups (repeated-measured ANOVA $P=0.03, P<0.01$ and $P<0.01$, respectively).

Thirty deaths occurred during follow-up (median, 41 months), including 11 cardiovascular deaths. One patient died after transfer to combined therapy, 5 patients died after transfer to HD alone and the remaining 24 patients died during PD therapy alone. Figure 2 shows a Kaplan-Meier analysis comparing patient survival between these three groups. (log-rank $P<0.01)$. Nineteen patients were censored due to renal transplantation and the median follow-up for that group was 13 months. Mortality was highest among patients continuing PD and was lower among those switching to combined therapy was among those switching directly to HD. Among patients switching dialysis modality because of inadequate dialysis and/or fluid overload, 1 patient died after transfer to combined therapy and 1 patient died after transferring directly to HD alone. Kaplan-Meier analysis revealed no differences in patient survival between these two subgroups (log-rank $\mathrm{P}=0.18$, Fig. 3 ).

\section{Discussion}

We conducted a multicenter prospective observational cohort study to compare patient outcomes between patients who switched from PD alone to combined therapy with PD and HD and patients who switched directly to HD. No significant differences were observed with respect to survival outcomes between the two groups. We could not conduct more detailed analysis, e.g. multivariate analysis, to confirm the effects of dialysis modality on patient outcome due to the small number of outcomes, which was attributable to our inclusion of only patients who had newly started PD. To the best of our knowledge, this is the first prospective case-control study in the field of the combined therapy. Evidence has been accumulating that both inadequate dialysis and volume overload are significantly resolved after switching from PD alone to combined therapy (7-12). Our previous retrospective multicenter study included 104 patients who switched from PD alone to combined therapy with PD and HD, and revealed 
that body weight and serum creatinine decreased, whereas hemoglobin levels increased during 3 months of combined therapy (7). In addition, urinary volume decreased, whereas ultrafiltration rate remained unchanged. Interestingly, D/P Cr decreased significantly, suggesting protective effects for the peritoneal membrane. However, all such studies, including our previous one, targeted only patients starting combined therapy with PD and HD, and thus lacked a control group.

We found that reasons for changing dialysis modality differed significantly between the two groups, with inadequate dialysis and/or fluid overload as the reason in $66 \%$ of transfers to combined therapy, compared to only $29 \%$ for direct transfers to HD. These findings revealed that patients suffering from inadequate dialysis or volume overload switched to combined therapy because they could continue PD. Conversely, the proportion of cases with this reason was lower and reasons for not continuing PD such as difficulty performing PD, peritonitis and exit-site infection, pleuroperitoneal communication and abdominal disorder or surgery, were more frequent among patients who directly switched to HD. Interestingly, patients who directly transferred to HD were older and had a lower BMI than those who transferred to combined therapy at the start of PD. We therefore performed a subgroup analysis for only those patients changing dialysis modality due to inadequate dialysis and/or fluid overload, i.e. those for whom PD was sustainable, and found that mortality among the two groups was similar. Further study with a larger number of outcomes is needed to compare clinical outcomes between patients who transfer to combined therapy and those who directly transfer to HD.

This study did not assess the efficacy of dialysis. The JSDT guideline (5) recommends that adequacy of dialysis should be determined using the concept of body fluid clear space in combined therapy $(5,13)$, but established methods to assess the combine efficacy of PD and HD remain lacking. Although Kt/V was used for the assessment of dialysis adequacy both in PD and HD patients, its definitions as applied these two treatments are totally different (14). We found that urea nitrogen and serum creatinine were decreased not among patients transferred to combined therapy, but among those directly transferred to HD. In addition, urinary volume after switching dialysis modality nearly disappeared. We thus speculated that dialysis adequacy for small-molecule uremic toxins was superior among patients who transferred directly to $\mathrm{HD}$ alone.

Several limitations to the present study must be considered. First, the number of outcomes was very small, as mentioned above. The comparison of patient outcomes, particularly using multivariate analysis, between patients who switched to combined therapy and those who switched directly to HD were therefore limited. Second, some degree of selection bias could not be avoided. because the timing of changing modality and selection of the type of new modality, especially in terms of combined therapy or $\mathrm{HD}$ alone, were left to the discretion of the treating physicians. On the other hand, a strength of this study was the multicenter design as a prospective observational cohort study of incident PD patients, allowing us to compare clinical outcomes between patients transferred to combined therapy and those transferred directly to HD.

\section{Conclusions}


This is the first report comparing patient survival and changes in several clinical parameters among patients who transferred from PD alone to either combined therapy or directly to HD. Although the comparison of patient survival was difficult because of the relatively small number of deaths, PD patients suffering from inadequate dialysis and/or volume overload were clearly found to be able to continue PD therapy safely by switching to combined therapy. Further study with a larger number of outcomes is needed to confirm differences in clinical outcomes between these two groups.

\section{Abbreviations}

PD, Peritoneal dialysis; RRT, renal replacement therapy; RRF, residual renal function; QOL, quality of life; $H D$, hemodialysis; EARTH, the Evaluation of the Adequacy of Renal replacement Therapy; ESRD, endstage renal disease; SGA, subjective global assessment; ESA, erythropoietin-stimulating agent, BP, blood pressure; $\mathrm{D} / \mathrm{P} \mathrm{Cr}$, the dialysate-to-plasma creatinine ratio; $\mathrm{PET}$, peritoneal equilibration test; JSDT, the Japanese Society for Dialysis Therapy; SD, standard deviation; IQR, interquartile range; ANOVA, analysis of variance; $\mathrm{CGN}$, chronic glomerulonephritis; PKD, polycystic kidney disease; BMI, body mass index

\section{Declarations}

Ethics approval and consent to participate

The ethics committee at Jikei University Hospital (approval number: 20-180 5470) and each participating hospital approved this study protocol, and all patients provided written informed consent to participate.

Consent for publication

Not applicable.

Availability of data and materials

The datasets used and/or analyzed during the current study are available from the corresponding author on reasonable request.

Competing interests

Y.M. has received scholarship funds from Baxter International, Inc. and Terumo Corporation. T.S. has received scholarship funds from Baxter International, Inc. and Terumo Corporation. K.S. has received advisory fees from JMS Co., Ltd. T.H. works in the Department of Pathophysiology and Therapy in Chronic Kidney Disease in positions endowed by Baxter International, Inc. at the Jikei University School of Medicine. M.N. has received research grants from Baxter International, Inc. The funders played no role in study design, data collection and analysis, decision to publish, or preparation of the manuscript. No other authors have any conflicts of interest to declare.

Funding 
This study was supported by grants from the Kidney Foundation, Japan. The funders played no roles in the study design, data collection and analysis, decision to publish, or preparation of the manuscript.

Authors' contributions

Research idea and study design: Y.M., K.Y., C.H., Y.T., K.S., Y.K., M.R., T.S., and M.N.; data acquisition: Y.M., K.Y., C.H., Y.T., K.S., Y.K., M.R. and T.S.; data analysis/interpretation: Y.M., K.Y. and M.N.; statistical analysis: Y.M.; supervision or mentorship: T.S. and T.H. All authors have read and approved the final version of the manuscript.

Acknowledgements

The authors thank the participants in the study and all personnel at the institutions that participated in this survey.

\section{References}

1. Chaudhary K, Sangha H, Khanna R. Peritoneal dialysis first: Rationale. Clin J Am Soc Nephrol. 2011;6:447-56.

2. Peritoneal Dialysis Adequacy Work G. Clinical practice guidelines for peritoneal dialysis adequacy. Am J Kidney Dis. 2006;48(Suppl 1):98-129.

3. Clinical practice recommendations for peritoneal dialysis adequacy. Am J Kidney Dis. 2006;48(Suppl 1):130-58.

4. Lo WK, Bargman JM, Burkart J, Krediet RT, Pollock C, Kawanishi H, et al. Guideline on targets for solute and fluid removal in adult patients on chronic peritoneal dialysis. Perit Dial Int. 2006;26:5202.

5. Working Group Committee for Preparation of Guidelines for Peritoneal Dialysis JSDT, Japanese Society for Dialysis T. 2009 japanese society for dialysis therapy guidelines for peritoneal dialysis. Ther Apher Dial. 2010;14:489-504.

6. Nitta K, Masakane I, Hanafusa N, Taniguchi M, Hasegawa T, Nakai S, et al. Annual dialysis data report 2017, jsdt renal data registry. Renal Replacement Therapy. 2019;5:53.

7. Maruyama Y, Yokoyama K, Nakayama M, Higuchi C, Sanaka T, Tanaka Y, et al. Combined therapy with peritoneal dialysis and hemodialysis: A multicenter retrospective observational cohort study in japan. Blood Purif. 2014;38:149-53.

8. Matsuo N, Yokoyama K, Maruyama Y, Ueda Y, Yoshida H, Tanno Y, et al. Clinical impact of a combined therapy of peritoneal dialysis and hemodialysis. Clin Nephrol. 2010;74:209-16.

9. Kanda R, lo H, Nakata J, Makita Y, Sasaki Y, Matsumoto M, et al. Evaluation of long-term combination therapy with peritoneal dialysis and hemodialysis. Ther Apher Dial. 2017;21:180-4.

10. Kawanishi H, Hashimoto Y, Nakamoto H, Nakayama M, Tranaeus A. Combination therapy with peritoneal dialysis and hemodialysis. Perit Dial Int. 2006;26:150-4. 
11. Moriishi M, Kawanishi H, Tsuchiya S. Impact of combination therapy with peritoneal dialysis and hemodialysis on peritoneal function. Adv Perit Dial. 2010;26:67-70.

12. Maruyama Y. Does combined therapy with peritoneal dialysis and hemodialysis improve prognosis? Contrib Nephrol. 2018;196:64-70.

13. Yamashita AC. A kinetic model for peritoneal dialysis and its application for complementary dialysis therapy. Contrib Nephrol. 2012;177:3-12.

14. Waniewski J, Lindholm B. Fractional solute removal and kt/v in different modalities of renal replacement therapy. Blood Purif. 2004;22:367-76.

\section{Tables}

Table 1. Baseline characteristics. 


\begin{tabular}{|c|c|c|c|c|c|c|}
\hline & $\begin{array}{l}\text { No. of } \\
\text { missing } \\
\text { value [\%] }\end{array}$ & $\begin{array}{l}\text { All } \\
\text { patients }\end{array}$ & $\begin{array}{l}\text { Patients } \\
\text { continued } \\
\text { PD }\end{array}$ & $\begin{array}{l}\text { Patients } \\
\text { transferred to } \\
\text { combined } \\
\text { therapy }\end{array}$ & $\begin{array}{l}\text { Patients } \\
\text { directly } \\
\text { transferred to } \\
\text { HD }\end{array}$ & P \\
\hline $\mathrm{N}$ & & 176 & $94(53 \%)$ & 47 (27\%) & $35(20 \%)$ & \\
\hline Male [\%] & $0(0 \%)$ & $\begin{array}{l}125 \\
(71 \%)\end{array}$ & $65(69 \%)$ & 39 (83\%) & $21(60 \%)$ & 0.06 \\
\hline Age [yr] & $0(0 \%)$ & $60 \pm 15$ & $61 \pm 17$ & $55 \pm 10$ & $64 \pm 14$ & 0.03 \\
\hline BMI $\left[\mathrm{kg} / \mathrm{m}^{2}\right]$ & $1(0.6 \%)$ & $\begin{array}{l}22.8 \pm \\
3.2\end{array}$ & $22.4 \pm 3.2$ & $23.8 \pm 3.3$ & $22.3 \pm 2.8$ & 0.03 \\
\hline $\begin{array}{l}\text { Systolic BP } \\
\text { [mmHg] }\end{array}$ & $1(0.6 \%)$ & $\begin{array}{l}143 \pm \\
22\end{array}$ & $144 \pm 24$ & $140 \pm 18$ & $145 \pm 20$ & 0.55 \\
\hline $\begin{array}{l}\text { Diastolic BP } \\
\text { [mmHg] }\end{array}$ & $2(1.1 \%)$ & $78 \pm 15$ & $78 \pm 17$ & $80 \pm 14$ & $75 \pm 12$ & 0.31 \\
\hline $\begin{array}{l}\text { Urine volume } \\
\text { [mL/day] }\end{array}$ & $11(6.3 \%)$ & $\begin{array}{l}1230 \\
(980- \\
1800)\end{array}$ & $\begin{array}{l}1210 \\
950- \\
1740\end{array}$ & $\begin{array}{l}12101000- \\
1900)\end{array}$ & $\begin{array}{l}1300(950- \\
1880)\end{array}$ & 0.81 \\
\hline $\begin{array}{l}\text { Primary renal } \\
\text { disease }\end{array}$ & $0(0 \%)$ & & & & & 0.70 \\
\hline CGN & & $\begin{array}{l}56 \\
(32 \%)\end{array}$ & $28(30 \%)$ & $18(38 \%)$ & $10(29 \%)$ & \\
\hline Diabetes & & $\begin{array}{l}66 \\
(38 \%)\end{array}$ & 35 (37\%) & $17(36 \%)$ & $14(40 \%)$ & \\
\hline Hypertension & & $\begin{array}{l}27 \\
(15 \%)\end{array}$ & $13(13 \%)$ & $8(17 \%)$ & $6(17 \%)$ & \\
\hline PKD & & $5(3 \%)$ & $3(3 \%)$ & $0(0 \%)$ & $2(6 \%)$ & \\
\hline $\begin{array}{l}\text { Other or } \\
\text { unknown }\end{array}$ & & $\begin{array}{l}22 \\
(13 \%)\end{array}$ & $15(16 \%)$ & $4(9 \%)$ & $3(9 \%)$ & \\
\hline \multicolumn{7}{|l|}{ Comorbidities } \\
\hline $\begin{array}{l}\text { Cardiovascular } \\
\text { disease }\end{array}$ & $0(0 \%)$ & $\begin{array}{l}21 \\
(12 \%)\end{array}$ & $13(14 \%)$ & $5(11 \%)$ & $3(9 \%)$ & 0.68 \\
\hline $\begin{array}{l}\text { Cerebrovascular } \\
\text { disease }\end{array}$ & $0(0 \%)$ & $16(9 \%)$ & $11(12 \%)$ & $3(6 \%)$ & $2(6 \%)$ & 0.43 \\
\hline $\begin{array}{l}\text { Malignant } \\
\text { disease }\end{array}$ & $0(0 \%)$ & $10(6 \%)$ & $4(4 \%)$ & $4(9 \%)$ & $2(6 \%)$ & 0.59 \\
\hline \multicolumn{7}{|l|}{ Laboratory data } \\
\hline $\mathrm{Hb}[\mathrm{g} / \mathrm{dL}]$ & $5(2.8 \%)$ & $\begin{array}{l}9.6 \pm \\
1.3\end{array}$ & $9.5 \pm 1.3$ & $9.7 \pm 1.2$ & $9.7 \pm 1.3$ & 0.65 \\
\hline
\end{tabular}




\begin{tabular}{|c|c|c|c|c|c|c|}
\hline Alb $[\mathrm{g} / \mathrm{dL}]$ & $0(0 \%)$ & $\begin{array}{l}3.5 \pm \\
0.6\end{array}$ & $3.5 \pm 0.6$ & $3.5 \pm 0.5$ & $3.5 \pm 0.6$ & 0.99 \\
\hline UN [mg/dL] & $0(0 \%)$ & $\begin{array}{l}79.7 \pm \\
28.6\end{array}$ & $\begin{array}{l}80.0 \pm \\
24.7\end{array}$ & $76.5 \pm 38.0$ & $83.1 \pm 23.7$ & 0.59 \\
\hline $\mathrm{Cr}[\mathrm{mg} / \mathrm{dL}]$ & $0(0 \%)$ & $\begin{array}{l}8.9 \pm \\
2.4\end{array}$ & $8.7 \pm 2.5$ & $9.2 \pm 2.2$ & $9.1 \pm 2.5$ & 0.43 \\
\hline $\begin{array}{l}\beta 2- \\
\text { microglobulin } \\
{[\mathrm{mg} / \mathrm{L}]}\end{array}$ & $\begin{array}{l}49 \\
(27.8 \%)\end{array}$ & $\begin{array}{l}16.0 \pm \\
5.2\end{array}$ & $16.7 \pm 6.1$ & $14.7 \pm 3.3$ & $15.8 \pm 4.9$ & 0.20 \\
\hline \multicolumn{7}{|c|}{ Efficiency of PD } \\
\hline Total Kt/V & $14(8.0 \%)$ & $\begin{array}{l}1.67 \pm \\
0.49\end{array}$ & $\begin{array}{l}1.69 \pm \\
0.50\end{array}$ & $1.65 \pm 0.40$ & $1.65 \pm 0.56$ & 0.86 \\
\hline Renal Kt/V & $14(8.0 \%)$ & $\begin{array}{l}0.82 \pm \\
0.41\end{array}$ & $\begin{array}{l}0.84 \pm \\
0.43\end{array}$ & $0.79 \pm 0.37$ & $0.82 \pm 0.38$ & 0.79 \\
\hline $\mathrm{PD} \mathrm{Kt/V}$ & $14(8.0 \%)$ & $\begin{array}{l}0.84 \pm \\
0.34\end{array}$ & $\begin{array}{l}0.85 \pm \\
0.35\end{array}$ & $0.86 \pm 0.30$ & $0.83 \pm 0.39$ & 0.92 \\
\hline $\mathrm{D} / \mathrm{P} \mathrm{Cr}$ & $9(5.1 \%)$ & $\begin{array}{l}0.60 \pm \\
0.12\end{array}$ & $\begin{array}{l}0.61 \pm \\
0.12\end{array}$ & $0.58 \pm 0.12$ & $0.59 \pm 0.10$ & 0.46 \\
\hline \multicolumn{7}{|c|}{$\begin{array}{l}\text { Abbreviations: PD, peritoneal dialysis; } \mathrm{HD} \text {, hemodialysis; BMI, body mass index; } \mathrm{BP} \text {, blood pressure; } \\
\text { CGN, chronic glomerulonephritis; PKD, polycystic kidney disease; Hb, hemoglobin; Alb, serum albumin; } \\
\text { UN, blood urea nitrogen; } \mathrm{Cr} \text {, creatinine; D/P Cr, dialysate-to-plasma ratio of creatinine. }\end{array}$} \\
\hline
\end{tabular}

Table 2. Changes in clinical and biochemical parameters. 


\begin{tabular}{|c|c|c|c|c|c|c|c|c|c|}
\hline \multirow[t]{2}{*}{ Variables } & \multicolumn{4}{|c|}{$\begin{array}{l}\text { Patients transferred to } \\
\text { combined therapy }\end{array}$} & \multicolumn{4}{|c|}{$\begin{array}{l}\text { Patients directly transferred } \\
\text { to HD }\end{array}$} & \multirow[t]{2}{*}{$\mathrm{p}^{\ddagger}$} \\
\hline & $\begin{array}{l}\text { Before } \\
\text { transfer }\end{array}$ & $\begin{array}{l}\text { After } \\
\text { transfer }\end{array}$ & $p^{\dagger}$ & $\mathrm{n}$ & $\begin{array}{l}\text { Before } \\
\text { transfer }\end{array}$ & $\begin{array}{l}\text { After } \\
\text { transfer }\end{array}$ & $p^{\dagger}$ & $\mathrm{n}$ & \\
\hline BMI $\left[\mathrm{kg} / \mathrm{m}^{2}\right]$ & $25.1 \pm 3.2$ & $\begin{array}{l}24.2 \pm \\
3.2\end{array}$ & 0.02 & 38 & $22.9 \pm 2.9$ & $\begin{array}{l}21.2 \pm \\
2.9\end{array}$ & $\begin{array}{l}< \\
0.01\end{array}$ & 24 & 0.10 \\
\hline $\begin{array}{l}\text { Systolic BP } \\
{[\mathrm{mmHg}]}\end{array}$ & $144 \pm 16$ & $134 \pm 19$ & 0.02 & 40 & $145 \pm 19$ & $\begin{array}{l}146 \pm \\
24\end{array}$ & 0.95 & 25 & 0.15 \\
\hline $\begin{array}{l}\text { Diastolic BP } \\
{[\mathrm{mmHg}]}\end{array}$ & $83 \pm 14$ & $75 \pm 11$ & $\dot{c}_{0.01}$ & 40 & $77 \pm 12$ & $80 \pm 13$ & 0.47 & 25 & 0.03 \\
\hline $\begin{array}{l}\text { Urinary volume } \\
\text { [mL/day] }\end{array}$ & $\begin{array}{l}840 \\
(240- \\
1100)\end{array}$ & $\begin{array}{l}100 \\
(10- \\
200)\end{array}$ & $\dot{0} 01$ & 33 & $\begin{array}{l}780 \\
(120- \\
1120)\end{array}$ & $\begin{array}{l}150 \\
(10- \\
500)\end{array}$ & $<.01$ & 18 & 0.07 \\
\hline $\mathrm{Hb}[\mathrm{g} / \mathrm{dL}]$ & $10.3 \pm 1.4$ & $\begin{array}{l}11.2 \pm \\
1.6\end{array}$ & $\dot{c}_{0.01}$ & 40 & $10.3 \pm 1.4$ & $\begin{array}{l}10.4 \pm \\
1.4\end{array}$ & 0.77 & 26 & 0.12 \\
\hline Alb $[\mathrm{g} / \mathrm{dL}]$ & $3.3 \pm 0.4$ & $3.3 \pm 0.5$ & 0.98 & 40 & $3.2 \pm 0.5$ & $3.1 \pm 0.7$ & 0.61 & 26 & 0.63 \\
\hline UN [mg/dL] & $\begin{array}{l}63.9 \pm \\
12.4\end{array}$ & $\begin{array}{l}63.4 \pm \\
15.7\end{array}$ & 0.83 & 42 & $\begin{array}{l}72.3 \pm \\
22.1\end{array}$ & $\begin{array}{l}50.5 \pm \\
14.1\end{array}$ & $\begin{array}{l}< \\
0.01\end{array}$ & 27 & $\begin{array}{l}< \\
0.01\end{array}$ \\
\hline $\mathrm{Cr}[\mathrm{mg} / \mathrm{dL}]$ & $13.3 \pm 3.5$ & $\begin{array}{l}13.8 \pm \\
3.1\end{array}$ & 0.13 & 42 & $11.2 \pm 3.2$ & $9.5 \pm 2.6$ & $\begin{array}{l}<.01 \\
0.01\end{array}$ & 27 & $<.01$ \\
\hline $\begin{array}{l}\beta 2 \\
\text { microglobulin } \\
\text { [mg/L] }\end{array}$ & $29.1 \pm 8.2$ & $\begin{array}{l}32.0 \pm \\
7.6\end{array}$ & 0.03 & 30 & $23.1 \pm 8.7$ & $\begin{array}{l}26.5 \pm \\
7.2\end{array}$ & 0.02 & 18 & 0.79 \\
\hline \multicolumn{10}{|c|}{$\begin{array}{l}\text { Abbreviations: HD, hemodialysis; BMI, body mass index; } \mathrm{BP} \text {, blood pressure; } \mathrm{Hb} \text {, hemoglobin; Alb, } \\
\text { serum albumin; UN, blood urea nitrogen; Cr, creatinine. }\end{array}$} \\
\hline \multicolumn{10}{|c|}{ † Comparisons between before and after changing dialysis modality. } \\
\hline
\end{tabular}

\section{Figures}


Combined therapy [\%]

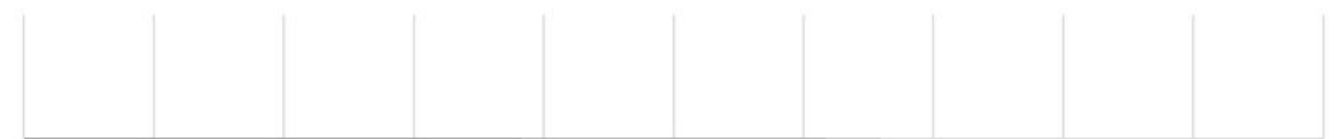

HD alone [\%]
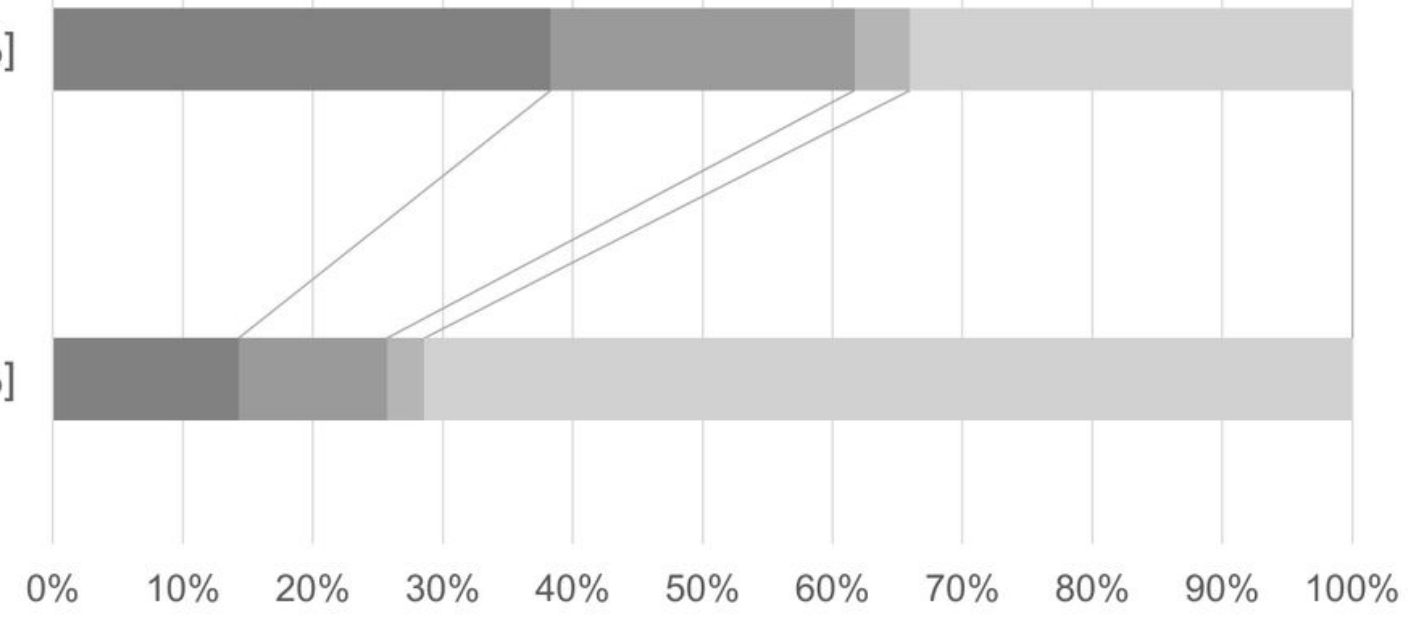

- Inadequate dialysis

- Fluid overload

Both inadequate dialysis and fluid overload

Others

\section{Figure 1}

Reasons for changes in dialysis modalities. Abbreviations: HD, hemodialysis. Other reasons included inguinal hernia operation $(n=1)$, exit-site infection $(n=1)$, preparation for renal transplantation $(n=1)$, initiating dialysis with combined therapy $(n=1)$ and unknown reason $(n=12)$ among patients transferred to combined therapy, and difficulty in performing $P D(n=7)$, pleuroperitoneal communication $(n=4)$, peritonitis $(n=4)$, exit-site infection $(n=3)$, abdominal disorder or surgery $(n=3)$ and unknown reason $(n=4)$ among those transferred directly to HD. 


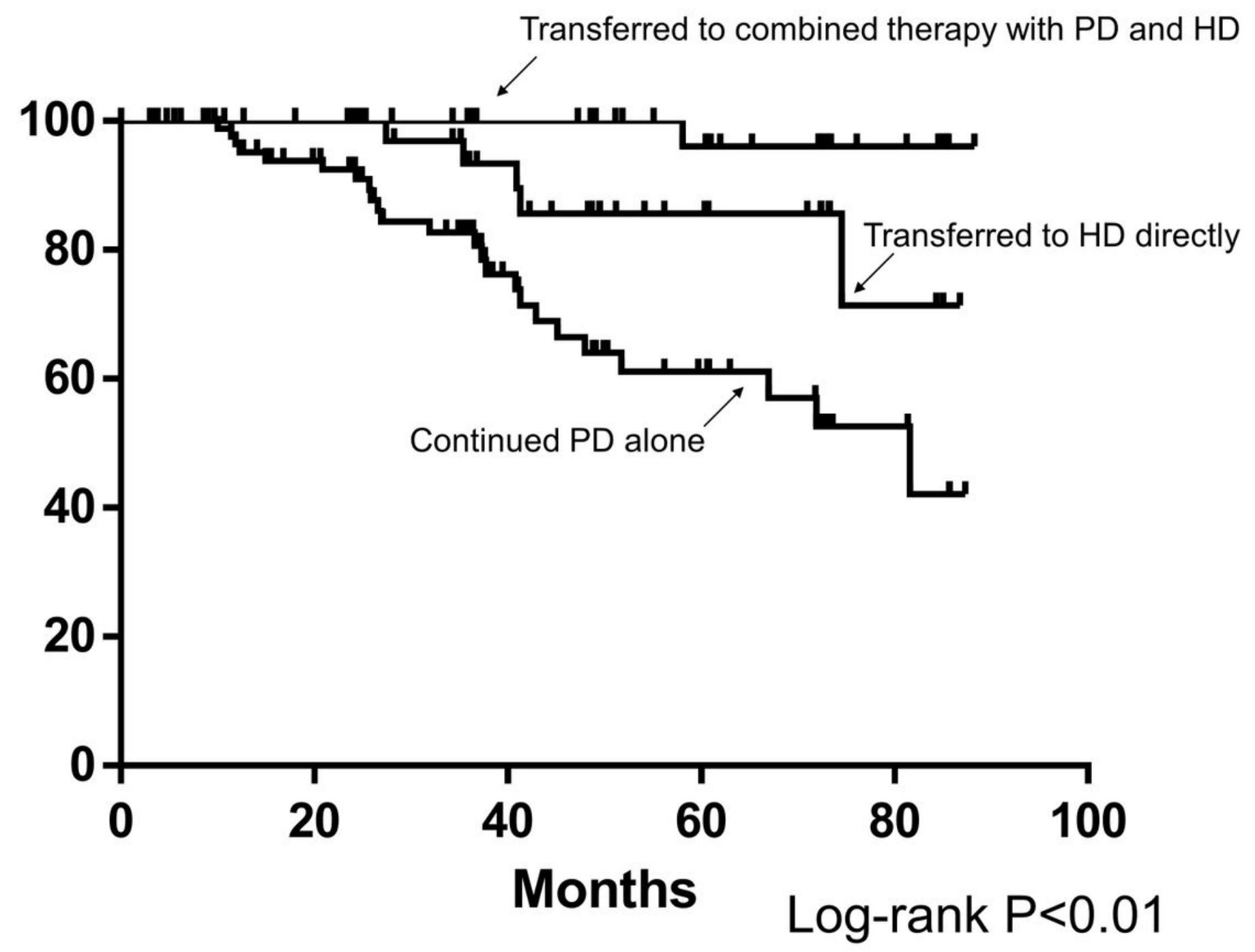

Figure 2

Kaplan-Meier analysis comparing patient survival between patients who continued PD, those transferred to combined therapy and those transferred directly to HD. Abbreviations: PD, peritoneal dialysis; HD, hemodialysis. 


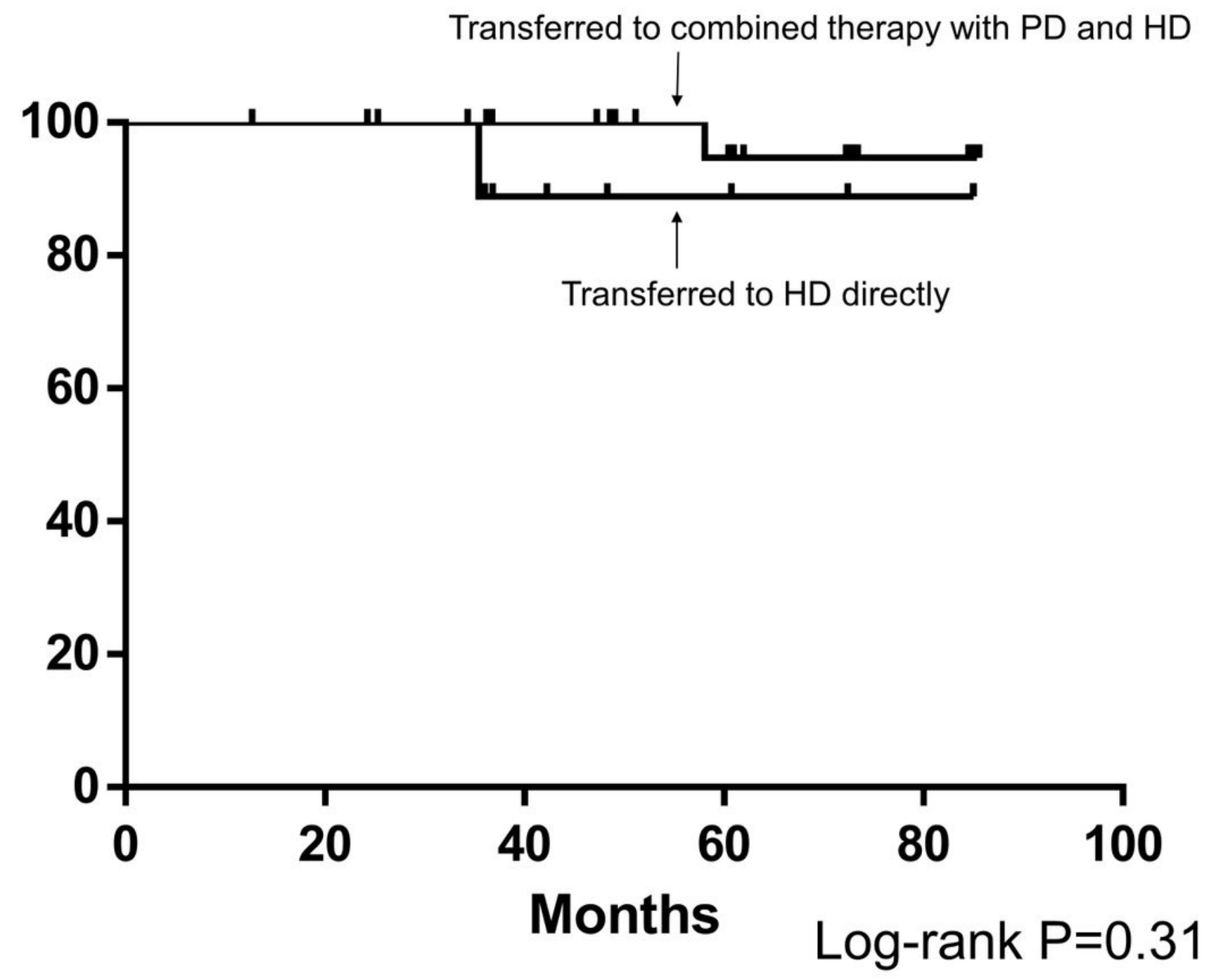

Figure 3

Kaplan-Meier analysis comparing patient survival between patients transferred to combined therapy and those transferred directly to HD among the subgroup of patients switching dialysis modality because of inadequate dialysis and/or fluid overload. Abbreviations: PD, peritoneal dialysis; HD, hemodialysis. 